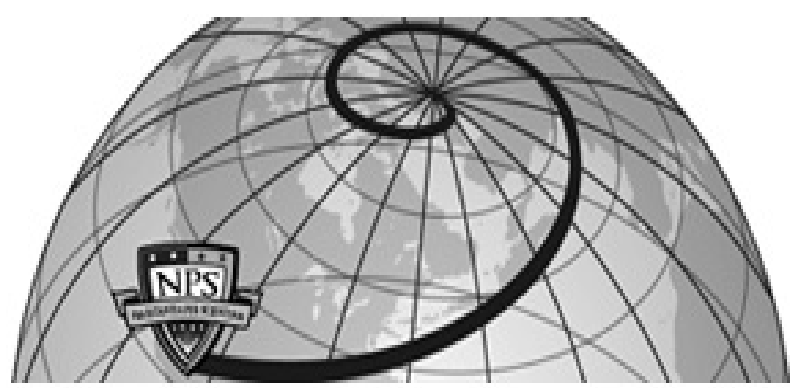

Calhoun: The NPS Institutional Archive DSpace Repository

\title{
Transient axial response of a gun launched rocket motor case during launch
}

Salinas, David; Ball, Robert E.

Monterey, California. Naval Postgraduate School

https://hdl.handle.net/10945/29564

This publication is a work of the U.S. Government as defined in Title 17, United States Code, Section 101. Copyright protection is not available for this work in the United States.

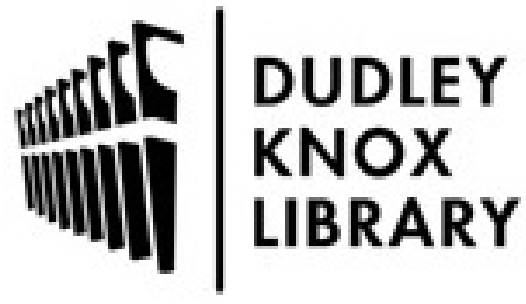

http://www.nps.edu/library
Calhoun is the Naval Postgraduate School's public access digital repository for research materials and institutional publications created by the NPS community. Calhoun is named for Professor of Mathematics Guy K. Calhoun, NPS's first appointed -- and published -- scholarly author.

Dudley Knox Library / Naval Postgraduate School 411 Dyer Road / 1 University Circle Monterey, California USA 93943 


\section{NAVAL POSTGRADUATE SCHOOL Monterey, California}



TRANSIENT AXIAL RESPONSE OF A GUN LAUNCHED ROCKET MOTOR CASE DURING LAUNCH

by

DAVID SALINAS

and

ROBERT E. BALL

29 January 1973

Approved for public release; distribution unl imited. 



\section{ABSTRACT :}

An analysis for the transient axial response of a gun launched motor case with unbonded propellant is performed. The present effort extends a previous work by including higher harmonics in the representation of the breech force at the aft end of the motor case. Including the higher harmonics leads to a more accurate representation of the actual breech force. The results of the analysis indicate that the dynamic effects on the internal axial force in the case are negligible for a breech force duration of 0.026 seconds. This is the same conclusion that was made in the previous work based upon a simple representation of the breech force.

This task was supported by:

Naval Weapons Center, China Lake, California, Work Request No. 2-3128

Robert H. Nunn, Chairman

Department of Mechanical Engineering
Jón'n M. Wozencraft Dean of Research 

TABLE OF CONTENTS

Abstract

i

Notation

i

Introduction

1

Analys is

2

Results and Discussion

8

Conclusions

9

References

10 

A

$A_{k}$

${ }^{B} k$

c

e

E

$f$

K

$\ell$

m

$P$

t

u

$\bar{u}$

u

U

v

$x, y$

$X, Y$

$\alpha$

$\gamma$

$\rho$

$\sigma$

$\omega$

area of motor case cross section

Fourier cosine coefficients of breech force

Fourier sine coefficients of breech force

speed of wave propagation

axial strain

Young's modulus of elasticity

axial force

constant

length

mass of motor case

breech force

time

deformation

displacement

rigid body displacement

transformation variable

transformation variable

coordinate axes

coordinate axes

time duration of breech force

constant

mass density of the motor case material

axial stress

constant 

This report examines the transient axial response of a gun-launched rocket motor, with unbonded propellant, during the launch phase. It is part of a continuing effort to develop structural design procedures for gun-launched rockets. In a previous report (Ref. 1), an analysis for the time-dependent axial force distribution in the motor case was performed in which the force at the breech end of the case was approximated by a one-half sine wave over the duration of the loading. That analysis established that for the one-half sine wave input, a time duration of .012 seconds leads to negligible dynamic effects, i.e., for a one-half sine wave of .012 seconds duration, the internal axial force at any location along the case appears as a duplicate of the breech force, but of smaller magnitude. It was shown, however, that decreasing the time of the force duration to .0012 seconds leads to significant dynamic effects. This result indicated that higher harmonics in the breech force could cause important dynamic effects. Since the actual breech force is not a simple half sine wave, but in fact is a complicated function of time, an investigation was made to consider the problem further.

To account for the higher harmonics in the breech-force, the analys is decomposes the actual force into a Fourier series with 27 terms. This force is applied to the case, and the internal axial force is computed at several locations along the case over the duration of the loading. This analysis then establishes the contribution of the higher harmonics in the breech force to the dynamic stresses in the bar. The analysis is restricted to the free-free motor case. 

In the figure below, $A B$ is the motor case, treated as a onedimensional bar, under the applied breech force $P(t)$. The actual displacement of any point of the bar with respect to the $X, Y$, fixed coordinate system is denoted $\bar{u}$. This motion consists of two parts, a rigid body motion $\tilde{u}$ and a strain-causing deformation $u$.

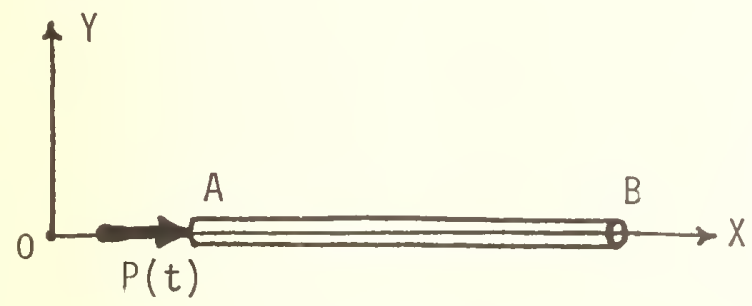

Then

$$
\bar{u}=\tilde{u}+u
$$

If $\mathrm{m}$ is the total mass of the bar, then the rigid body motion is

$$
\frac{d^{2} \tilde{u}}{d t^{2}}=\frac{P(t)}{m}
$$

The differential equation of motion for any point of the bar is

$$
\frac{\partial^{2} \bar{u}}{\partial t^{2}}-c^{2} \frac{\partial^{2} u}{\partial x^{2}}=0
$$

where $c$ is the speed of wave propagation, and $x$ is a coordinate axis parallel to $x$ moving with velocity $\stackrel{2}{u}$. The constant $c$ is given by

$$
c=\sqrt{\frac{E}{\rho}}
$$

where $E$ is Young's modulus of elasticity of the bar material and p its specific gravity. Combining equations (1) and (3) gives

$$
\frac{\partial^{2}}{\partial t^{2}}(\tilde{u}+u)-c^{2} \frac{\partial^{2} u}{\partial x^{2}}=0
$$



Substituting for $\frac{\partial^{2} \tilde{u}}{\partial t^{2}}$ from (2) yields,

$$
\frac{\partial^{2} u}{\partial t^{2}}+\frac{P(t)}{m}-c^{2} \frac{\partial^{2} u}{\partial x^{2}}=0 .
$$

With the notation ()$_{x x}$ denoting $\frac{\partial^{2}()}{\partial x^{2}}$, and ()$_{t t}$ denoting $\frac{\partial^{2}()}{\partial t^{2}}$, the governing differential equation is

$$
\begin{aligned}
u_{t t}-c^{2} u_{x x}=-\frac{P(t)}{m} & t>0, \\
& 0<x<\ell
\end{aligned}
$$

The initial conditions and boundary conditions for the free-free sys tem are

$$
\begin{array}{ll}
\text { I.C.'s: } u(x, 0)=0 & u_{t}(x, 0)=0 \\
\text { B.C.'s: } u_{x}(0, t)=\frac{P(t)}{A E} u_{x}(l, t)=0
\end{array}
$$

The solution of equations (5) through (7) gives the deformation of any point for any time greater than zero. The stress is then simply obtained from Hooke's Law, $\sigma=\mathrm{Eu}_{\mathrm{x}}$.

The solution method proceeds by transformation of the given system to a system with homogeneous boundary conditions. This is achieved by considering a solution in the form

$$
u(x, t)=v(x, t)+u(x, t) .
$$

Boundary condition equations (7) become

$$
\begin{aligned}
& v_{x}(0, t)=\frac{P(t)}{E A}-U_{x}(0, t) \\
& v_{x}(l, t)=-U_{x}(l, t)
\end{aligned}
$$

These equations become homogeneous when $U(x, t)$ is taken as

$$
U(x, t)=\left(x-\frac{x^{2}}{2 l}\right) \frac{P(t)}{A E}
$$



With equations (8) and (10), governing equations (5) through (7) become

$$
\begin{array}{ll}
v_{t t}-c^{2} v_{x x}=f(x, t) & \\
\text { I.C.'s: } v(x, 0)=-U(x, 0) & v_{t}(x, 0)=-U_{t}(x, 0) \\
\text { B.C.'s: } v_{x}(0, t)=0 & v_{t}(l, t)=0
\end{array}
$$

where

$$
\begin{aligned}
f(x, t) & =-U_{t t}+c^{2} U_{x x}-\frac{P(t)}{\rho \ell A} \\
& =-\left(x-\frac{x^{2}}{2 l}\right) \frac{P_{t}}{A E}-\frac{2 P}{\rho l A}
\end{aligned}
$$

A Fourier series solution which satisfies boundary conditions (13) is assumed for $v(x, t)$, i.e.,

$$
v(x, t)=\sum_{n=0}^{\infty} v_{n}(t) \cos \frac{n \pi x}{l}
$$

Accordingly, equations (11) and (12) become

$$
\begin{aligned}
& \frac{d^{2} v_{n}(t)}{d t^{2}}+\omega_{n}^{2} v_{n}(t)=f_{n}(t) \quad n=1,2, \ldots \\
& \text { I.C.'s: } v_{n}(0)=0 \\
& \frac{d v_{n}}{d t}(0)=\frac{2}{l} \int_{0}^{l} \frac{\left(x-\frac{x^{2}}{2 l}\right)}{E A} \frac{d P(t)}{d t} \cos \frac{n \pi x}{l} d x
\end{aligned}
$$

where

$$
f_{n}(t)=\frac{2}{l} \int_{0}^{l} f(x, t) \cos \frac{n \pi x}{l} d x \text {, }
$$

and

$$
\omega_{n}=\frac{n \pi c}{l}
$$



To this point the analysis is identical to that presented in reference 1. In that analysis, $P(t)$ was approximated as a half sine wave $P_{0} \sin \pi t / \alpha$; here, the breech force is approximated by the Fourier expansion,

$$
P(t)=A_{0}+\sum_{k=1}^{N}\left\{A_{k} \cos \frac{2 k \pi t}{\alpha}+B_{k} \sin \frac{2 k \pi t}{\alpha}\right\}
$$

For the linear system, the response due to equation (20) is obtained by superposition of individual terms .

(i) for the uniform force $A_{0}$ :

From equation (14), $f(x, t)=-\frac{2 P}{\rho \ell A}$. Then equation (18) gives $f_{n}=0$ for al1 $n$. The initial conditions are $v_{n}=0$, and $\dot{v}_{n}=0$ from equation (17), and hence $v_{n}(t)=0$. Then the stress is

$$
\sigma=E u_{x}=E U_{x}=\left(1-\frac{x}{l}\right) \frac{A_{0}}{A}
$$

This is the stress due to the "rigid body" acceleration for constant force.

(ii) for the cosine terms, $A_{k} \cos \frac{2 k \pi t}{\alpha}$ :

From equation (14) we obtain,

$$
f(x, t)=\left\{\frac{\left(x-\frac{x^{2}}{2 l}\right)}{E A} \cdot\left(\frac{2 k \pi}{\alpha}\right)^{2}-\frac{2 c^{2}}{E A l}\right\} \cdot A_{k} \cos \frac{2 k \pi t}{\alpha}
$$

Then equations (17) and (18) give

$$
\begin{aligned}
& \frac{d}{d t} v_{n}(0)=0 \\
& f_{n}(t)=-\frac{8 k^{2} l}{\alpha^{2} n^{2} E A} A_{k} \cos \frac{2 k \pi t}{\alpha}
\end{aligned}
$$



With equations (22) and (23), the solution of equation (16) is

$$
v_{n}(t)=\frac{k_{n}{ }^{2} A_{k}}{\pi^{2}\left(\gamma_{n}^{2}-1\right)}\left\{\cos \frac{2 k \pi t}{\alpha}-\cos \omega_{n} t\right\}
$$

where

$$
k_{n}=-\frac{2 l}{n^{2} \alpha^{2} E A}
$$

and

$$
\gamma_{n}=\frac{\omega_{n}}{\frac{2 \mathrm{k} \pi}{\alpha}} .
$$

Then the stress associated with $A_{k} \cos \frac{2 k \pi t}{\alpha}$ terms is

$$
\begin{aligned}
\sigma=E u_{x} & =E\left(v_{x}+u_{x}\right) \\
= & \sum_{y=1}^{\infty} \frac{2}{\pi n A} \cdot \frac{A_{k}}{\left(\gamma_{n}^{2}-1\right)}\left\{\cos \frac{2 k \pi t}{\alpha}-\cos \omega_{n} t\right\} \cdot \sin \frac{n \pi x}{\ell} \\
& +\left(1-\frac{x}{\ell}\right) \frac{A_{k}}{A} \cos \frac{2 k \pi t}{\alpha}
\end{aligned}
$$

The latter term in equation (27) is the contribution associated with the "rigid body" acceleration.

iii) for sine terms, $B_{k} \sin \frac{2 k \pi t}{\alpha}$ :

Equation (14) gives

$$
f(x, t)=\left\{\frac{x-\frac{x^{2}}{2 l}}{E A}\left(\frac{2 k \pi^{2}}{\alpha}\right)^{2}-\frac{2 c^{2}}{E A l}\right\} A_{k} \cos \frac{2 k \pi t}{\alpha}
$$

From equations (17) and (18),

$$
\begin{aligned}
& \frac{d}{d t} v_{n}(0)=-\frac{4 k \ell B_{k}}{E A n^{2} \pi \alpha} \\
& f_{n}(t)=\frac{8 k^{2} \ell}{\alpha^{2} n^{2} E A} B_{k} \sin \frac{2 k \pi t}{\alpha}
\end{aligned}
$$



The solution of equation (16) with equations (28) and

(29) is

$$
v_{n}(t)=\frac{2 K_{n} k B_{k} \alpha^{2}}{R_{n} \pi^{2}}\left\{\frac{\gamma_{n}^{2}-2}{\gamma_{n}^{2}-1}\right\} \cdot \sin \omega_{n} t+\frac{k_{n} \alpha^{2} B_{k}}{\pi^{2}\left(\gamma_{n}^{2}-1\right)} \sin \frac{2 k \pi t}{\alpha}
$$

where

$$
R_{n}=\frac{w_{n}}{(\pi / \alpha)}
$$

The stress associated with $B_{k} \sin \frac{2 k \pi t}{\alpha}$ is

$$
\begin{gathered}
\sigma=\sum_{n=1}^{\infty} \frac{2 B_{k}}{n \pi A}\left\{\frac{2 k}{R_{n}}\left(\frac{\gamma_{n}^{2}-2}{\gamma_{n}^{2}-1}\right) \sin \omega_{n} t+\frac{1}{\gamma_{n}^{2}-1} \sin \frac{2 k \pi t}{\alpha}\right\} \sin \frac{n \pi x}{\ell} \\
+\left(1-\frac{x}{\ell}\right) \frac{B_{k}}{A} \sin \frac{2 k \pi t}{\alpha}
\end{gathered}
$$

Aga in the latter term in equation (32) results from the "rigid body" acceleration.

The stress at any point is obtained as the superposition of equations (27), (27), and (32). 



\section{RESULTS AND DISCUSSION}

Equations (21), (27), and (32) for the stress have been evaluated on the NPS - IBM 360/67 digital computer for specific values of $A_{k}$ and $B_{k}$ obtained by a Fourier decomposition of the given breech force. This decomposition is done by the IBM subroutine FORIT on the computer. The present analysis resolved the breech force into 26 sine and cosine harmonics, i.e.,

$$
P(t)=A_{0}+\sum_{k=1}^{26}\left\{A_{k} \cos \frac{2 k \pi t}{\alpha}+B_{k} \sin \frac{2 k \pi t}{\alpha}\right\}
$$

The magnitude of the harmonic coefficients $A_{k}$ and $B_{k}$ depend upon the nature of the breech force. For this analysis, the force given in Fig. 1 of Ref. 2 was used. Approximation of that force by equation (33) leads to

\begin{tabular}{|ccc|}
\hline$k$ & $A_{k}$ & $B_{k}$ \\
\hline 0 & 14.1680 & 0. \\
1 & -8.6082 & 9.6038 \\
2 & -3.2336 & -4.3103 \\
3 & 1.3139 & -.8107 \\
4 & -.1162 & .1077 \\
5 & .1089 & -.1257 \\
6 & -.2036 & .3394 \\
7 & -.3478 & -.0886 \\
8 & -.3001 & -.1664 \\
9 & -.2229 & -.3071 \\
10 & .1728 & -.2293 \\
11 & .2260 & .1067 \\
12 & -.0425 & .3243 \\
13 & -.3157 & .2287 \\
\hline
\end{tabular}

\begin{tabular}{|ccc|}
\hline$k$ & $A_{k}$ & $B_{k}$ \\
\hline 14 & -.3164 & -.0186 \\
15 & -.1682 & -.0940 \\
16 & -.0552 & .0146 \\
17 & -.1202 & .0983 \\
18 & -.2053 & .0899 \\
19 & -.1821 & .0827 \\
20 & -.2162 & .0815 \\
21 & -.2723 & .0286 \\
22 & -.2164 & -.0294 \\
23 & -.1599 & .0250 \\
24 & -.2146 & .0638 \\
25 & -.2589 & -.0065 \\
26 & -.2162 & .0034 \\
\hline
\end{tabular}



A plot of equation (33) with the above values of $A_{k}$ and $B_{k}$ is given in Fig. 1 for a .026 second time duration of breech force. Figures 2 through 5 are the results for the stress in the bar due to the breech force shown in Fig. 1 as a function of time for $\frac{x}{\ell}$ ratios of $0,1 / 4,1 / 2$, and $3 / 4$, respectively. (The analysis is for the $5 \mathrm{in}$. steel shell of 0.19 in. thickness). Comparing Fig. 1 with Figs. 2 through 5 reveals that the internal force appears as a duplicate of the breech force, with the stress curves scaled versions of the force input. In Figs. 6 through 8, the contributing harmonics are individually displayed. The elastic dynamic effects are the small oscillations about each harmonic itself.

Figures 10 through 16 are the results of the analysis for a time duration of 0.0052 seconds for the brech force. This is a reduction in the actual duration by a factor of five. This sample problem was considered in order to assess the influence of the magnitude of the force duration. The elastic dynamic effects can be clearly seen in these figures. Note that the magnitude of stress has been significantly changed by the dynamic effects.

\section{CONCLUSIONS}

The results of this analysis (Figs. 1-5) show that dynamic effects are negligible for the breech force of 0.026 seconds time duration of Figure 1, Reference 2. Hence, when the propellant is not bonded to the motor case, the case responds to the breech force as if it were applied in a static sense, i.e., the maximum internal axial load in the case can be computed on the basis of the mass 

distribution and the maximum rigid body acceleration of the rocket. This is the same conclusion arrived at in Ref. 1 based on a simple one-half sine wave pulse; hence, accounting for the more complicated actual breech pressure pulse confirmed the original conclusion.

Further investigation (Figs. 10-14) verified the dependence of the dynamic effects on the presence of significant higher harmonic terms in the breech force. Such harmonics may be the result of shortening the time duration of loading, or by the presence of a local rapid perturbation of force on an otherwise acceptable smooth breech force input.

\section{REFERENCES}

1. Ba11, Robert E., and Salinas, David, "Analys is of a Three Inch Gun Launched Finned Motor Case," Naval Postgraduate School, NPS-57Bp-72011A, January 1972.

2. Ba11, Robert E., "Survivability of the Five-Inch Gun Launched Finned Motor Case," Naval Postgraduate School, NPS-57Bp72081A, August 1972. 



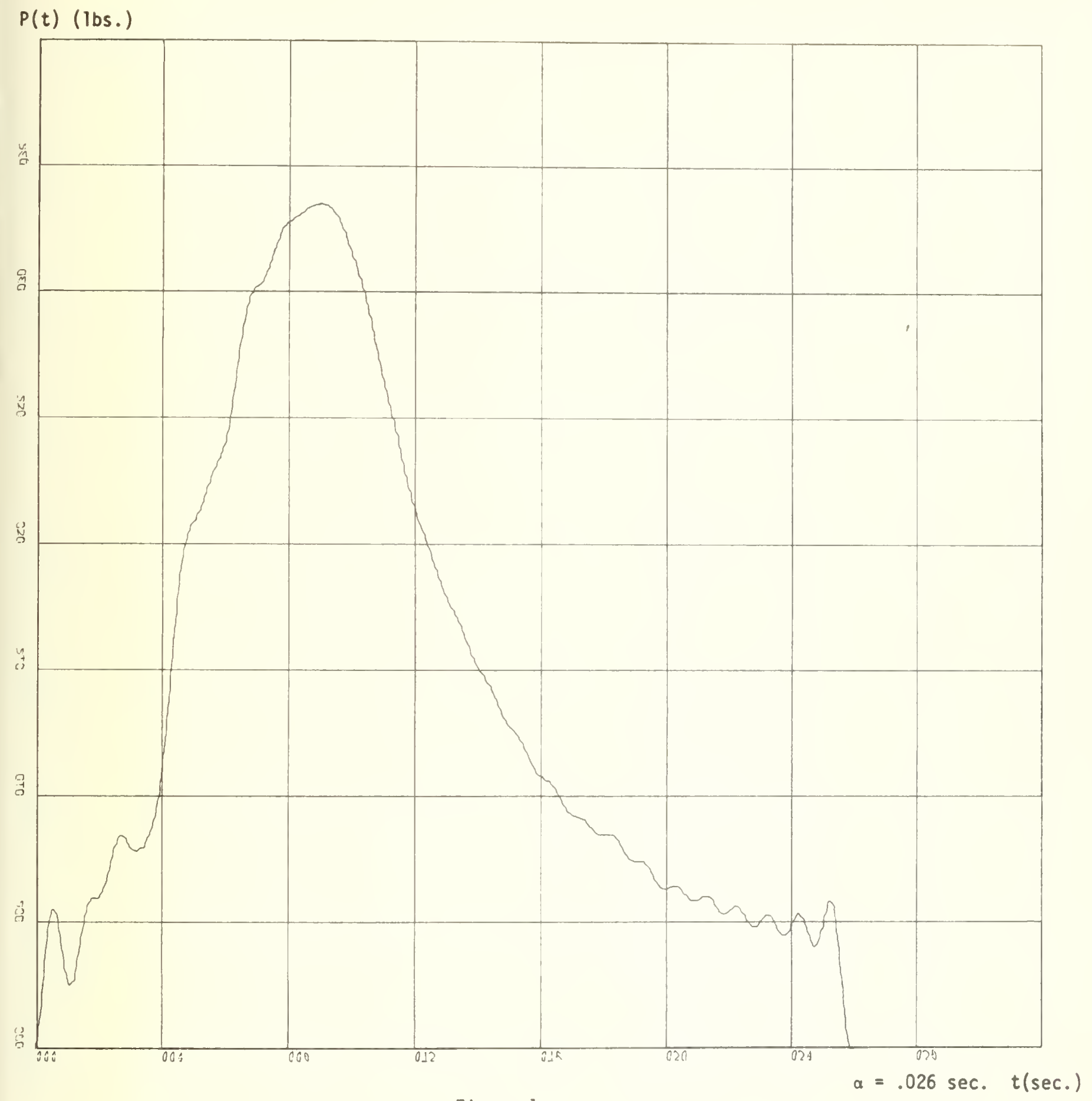

Figure 1

X-SCALE : 4. DOE-Q3 UNITS

$Y-S C A L E=:=5.0 Q E+Q 0$ UNITS

AXIAL WAUE PROPACATION-BREECH FORCE 

$\sigma(P S I)$



$X-S C A L E=: 4.00 E-03$ UNITS

$Y-S C A L F=3.00 E+01$ UNITS

AXIAL WAUE PROPAGATION-STRESSES AT $x / L=0$. 





Figure 3

$K-$ SCALF $=4.00 E-0.3$ UNITS

$Y-S C A L E=3 \cdot \square O E+\square \perp$ UNITS

AXIAL WAUE PRGPAGATIONN-STRESSES AT $X / L=1 / 4$ 

$\sigma$ (PSI)

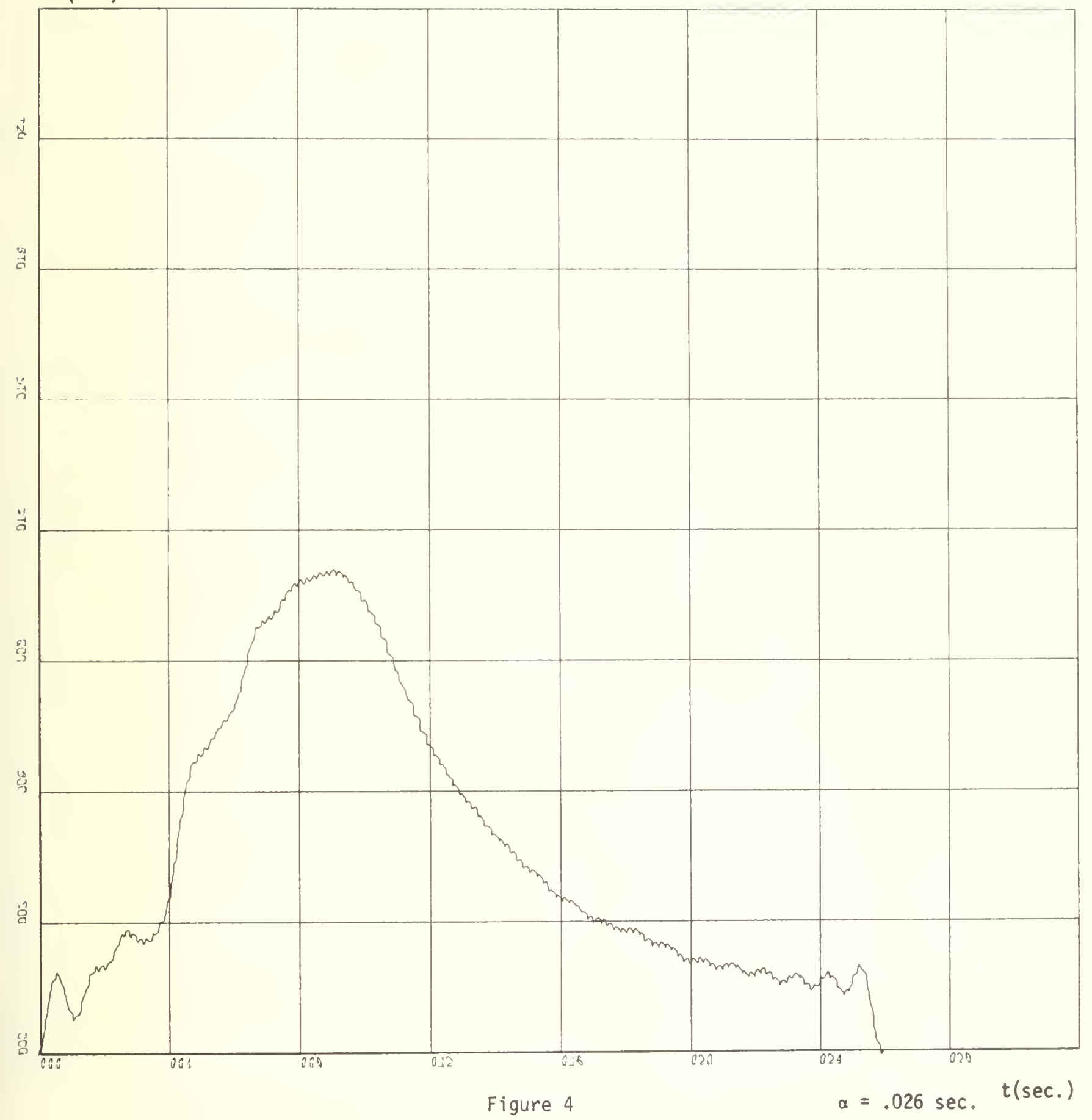

$K-$ SCALF $=4 ., Q D E-Q 3$ UNITS

$Y-S C A L E=3$, QQE + Q1 UNITS

AXIAL WAUE PROPAGATIGN-STRESSES AT $X / L=1 / 2$ 



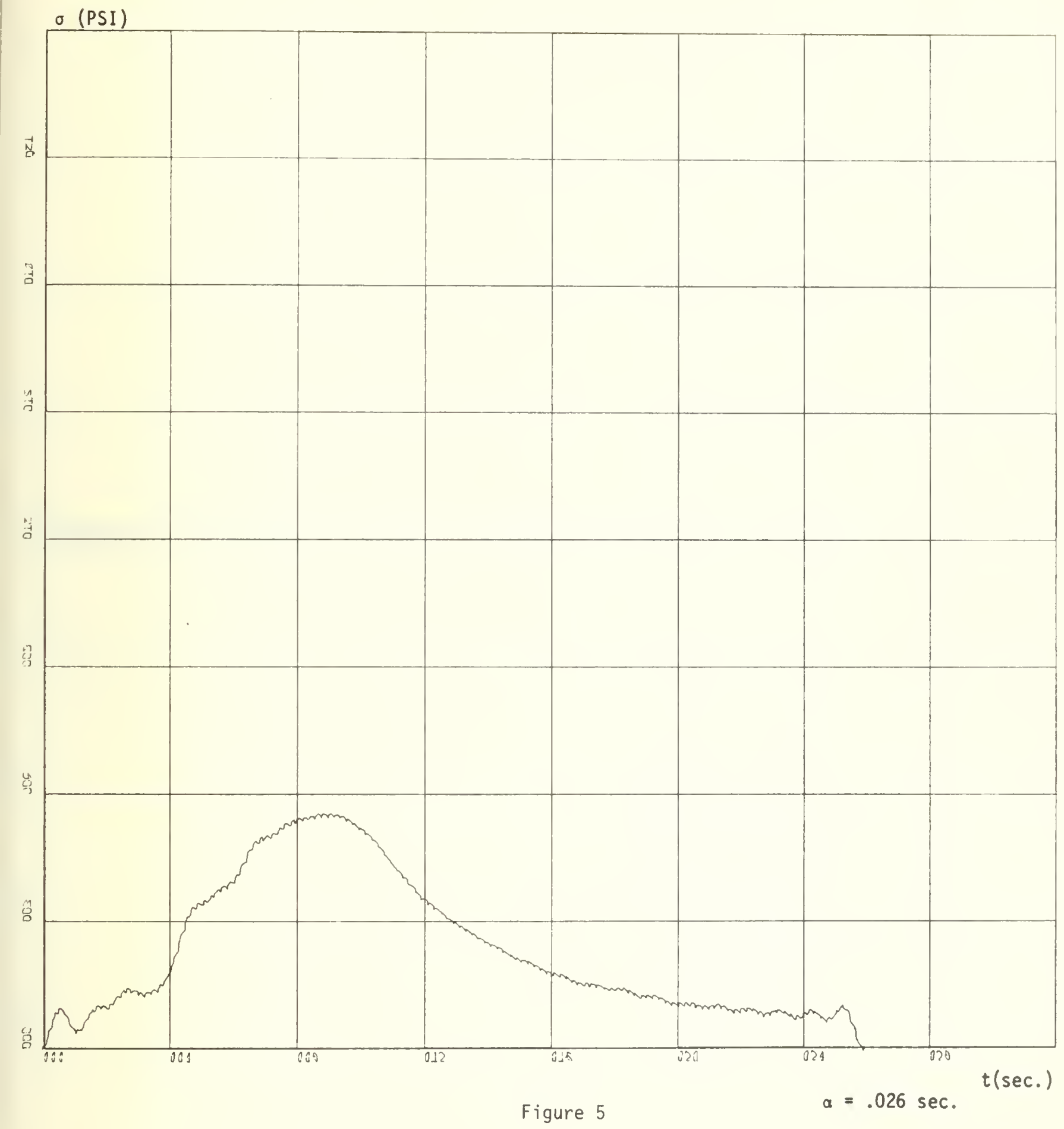

$x-$ SCAL. $:=4.00 E-03$ UN]TS

$Y-S C A L E:: 3, \square D E+D \perp$ LNITS

AXIAL HAUE PROPAGATION-STRESSES AT $K / L=3 / 4$ 



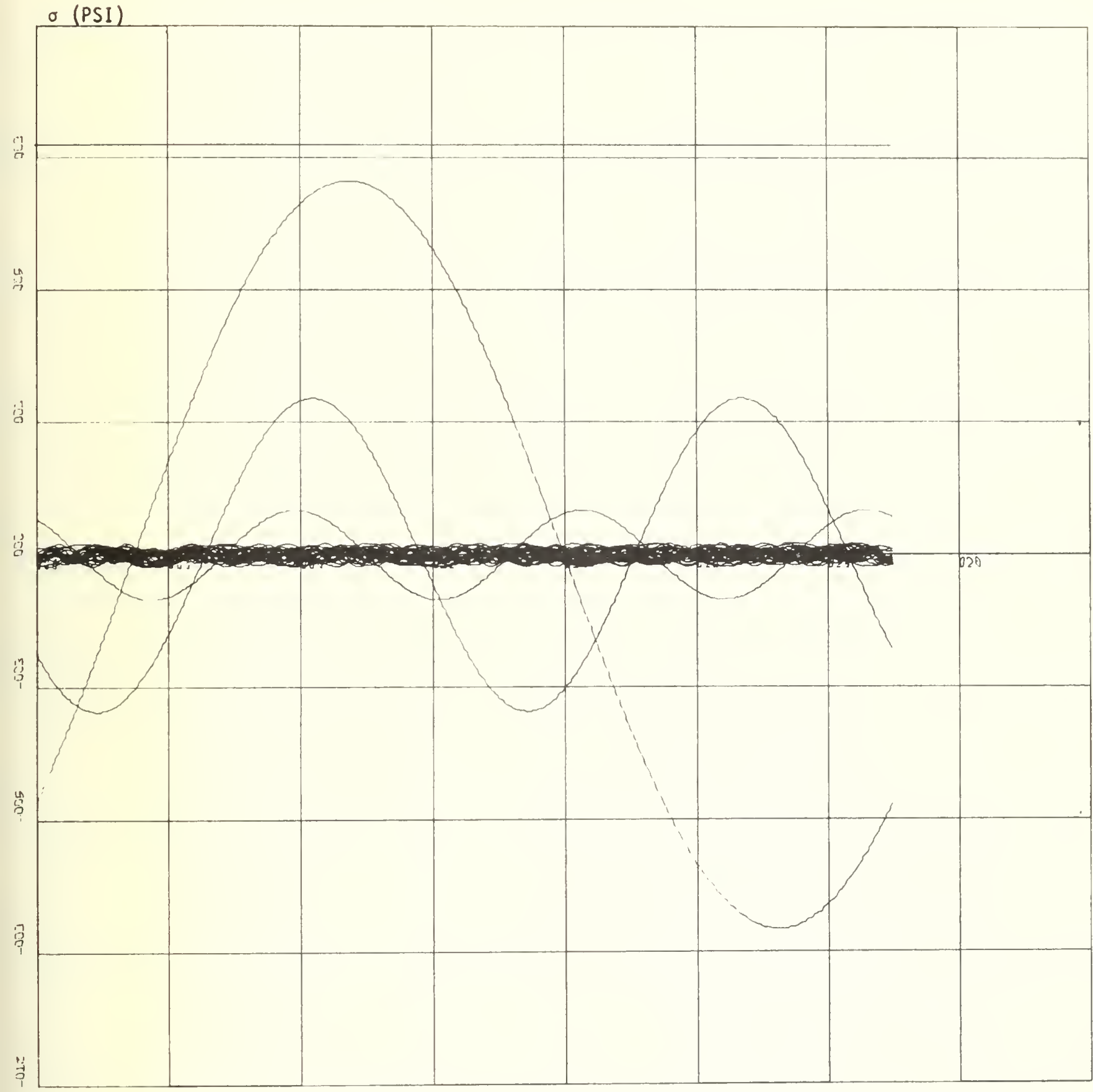

Figure 6

$\alpha=.026 \mathrm{sec}$.

Y - GCALF:4. DQE-D3 UNITS

$Y$-SCALE: $: 3$. QOEE + Q1 UNITS

AXIAL WAUE PRIPAGATIONN-HARMONICS at $x / \mathrm{L}=0$. 



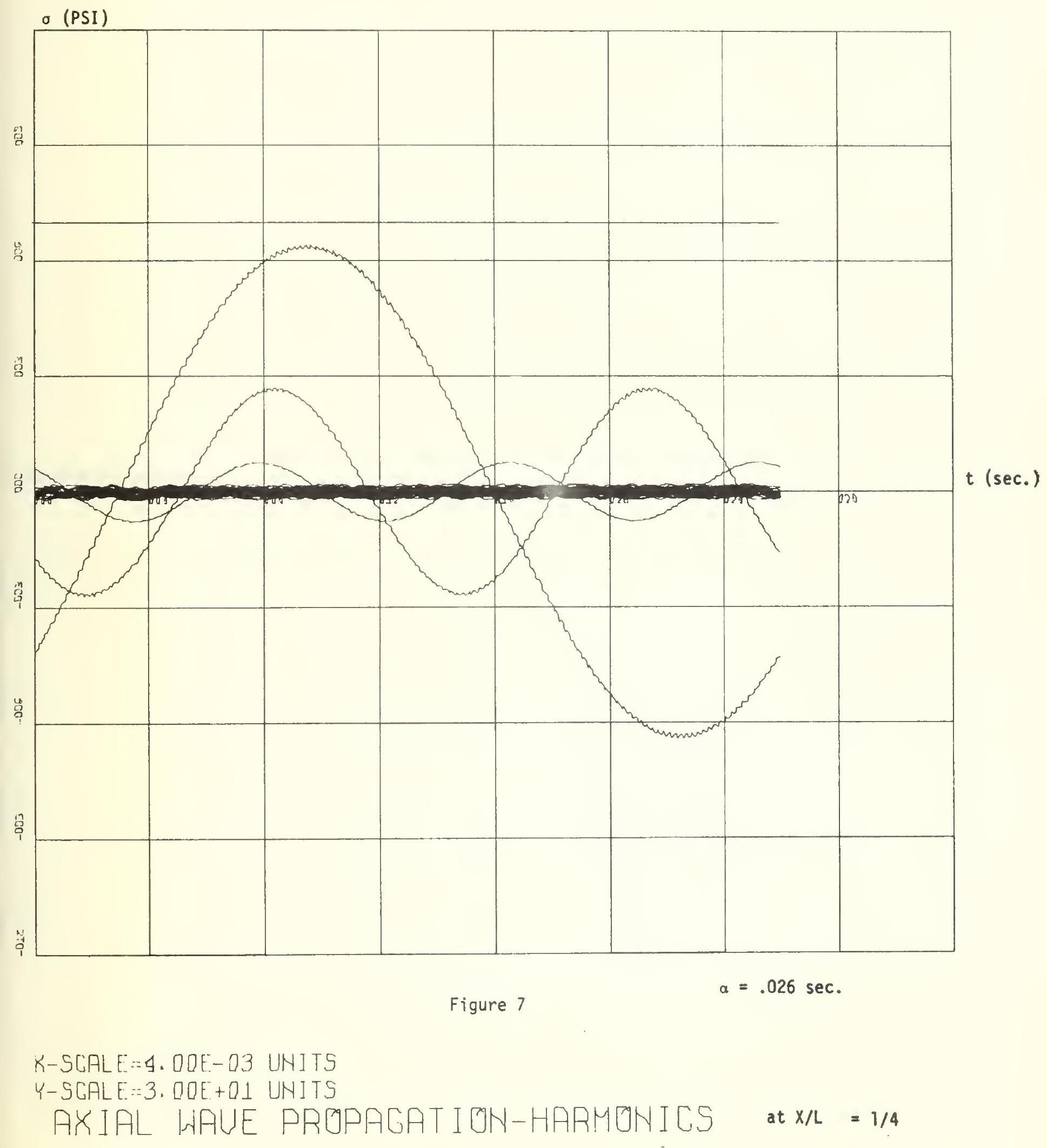



$\sigma$ (PSI)

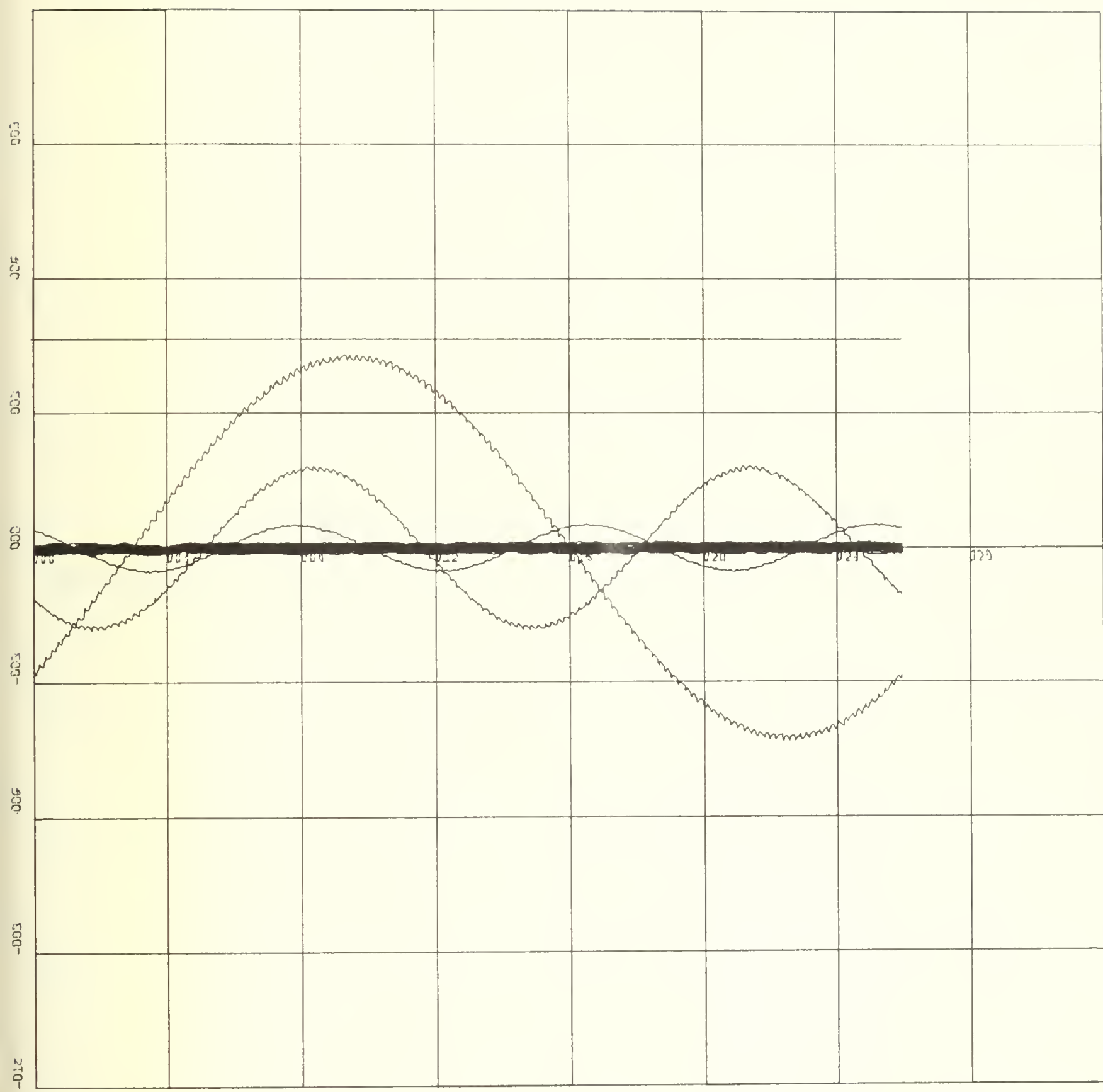

Figure 8

$\alpha=.026 \mathrm{sec}$.

$K-$ SCALE $=-4 \cdot$ QQEE-Q3 LINITS

$Y-5 C A L E=3, \square Q E+Q 1$ LNITS

AX'IAL WAUE PROPAGATION-HARMONICS at $\mathrm{x} / \mathrm{L}=1 / 2$ 

$\sigma(P S I)$

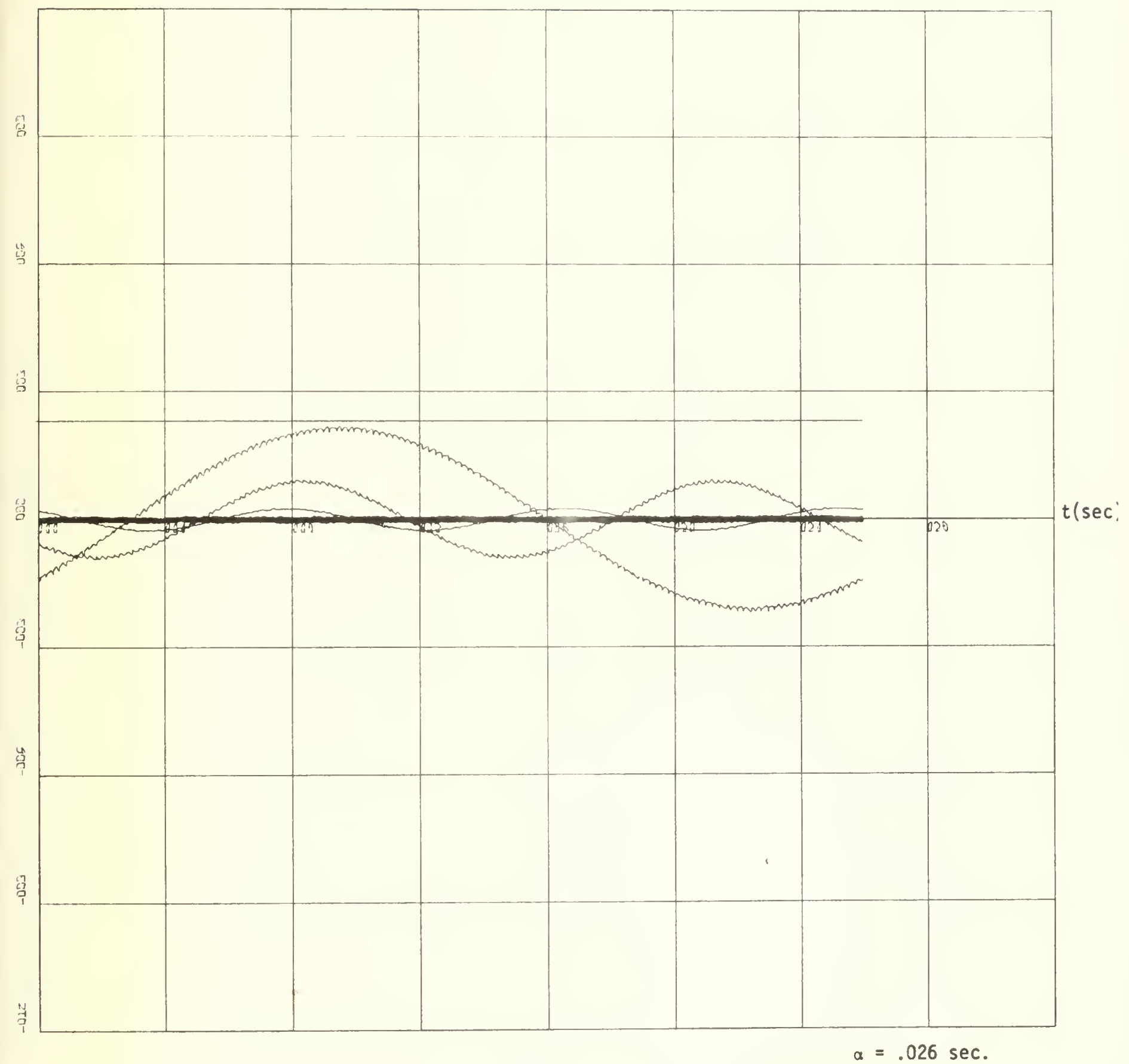

Figure 9

$X-$ SCAL E :=4. Q0E-03 UNITS

$Y-S C A L F=3 \cdot \square O E+\square \perp$ UNITS

AKIAL WAUE PROPACATION-HARMONICS at $\mathrm{x} / \mathrm{L}=\mathbf{z} / \mathrm{a}$ 



\section{$P(t)$ (1bs.)}



Figure 10

$n-$ STAL.F - - B. OQE - DA UNITS

Y-SLALF- - S. QQE + QO UNITS

AXIAL LIAUE PROPAGATIOIN-BREECH FORCE 

$\sigma$ (PSI)



Figure 11

X-SCALE - E. DQE-QA LNITS

Y-SCALF - 3. DOE. + L LNITS

AXIAL NAUE PROPAGATION-STRESSES AT X'LO 



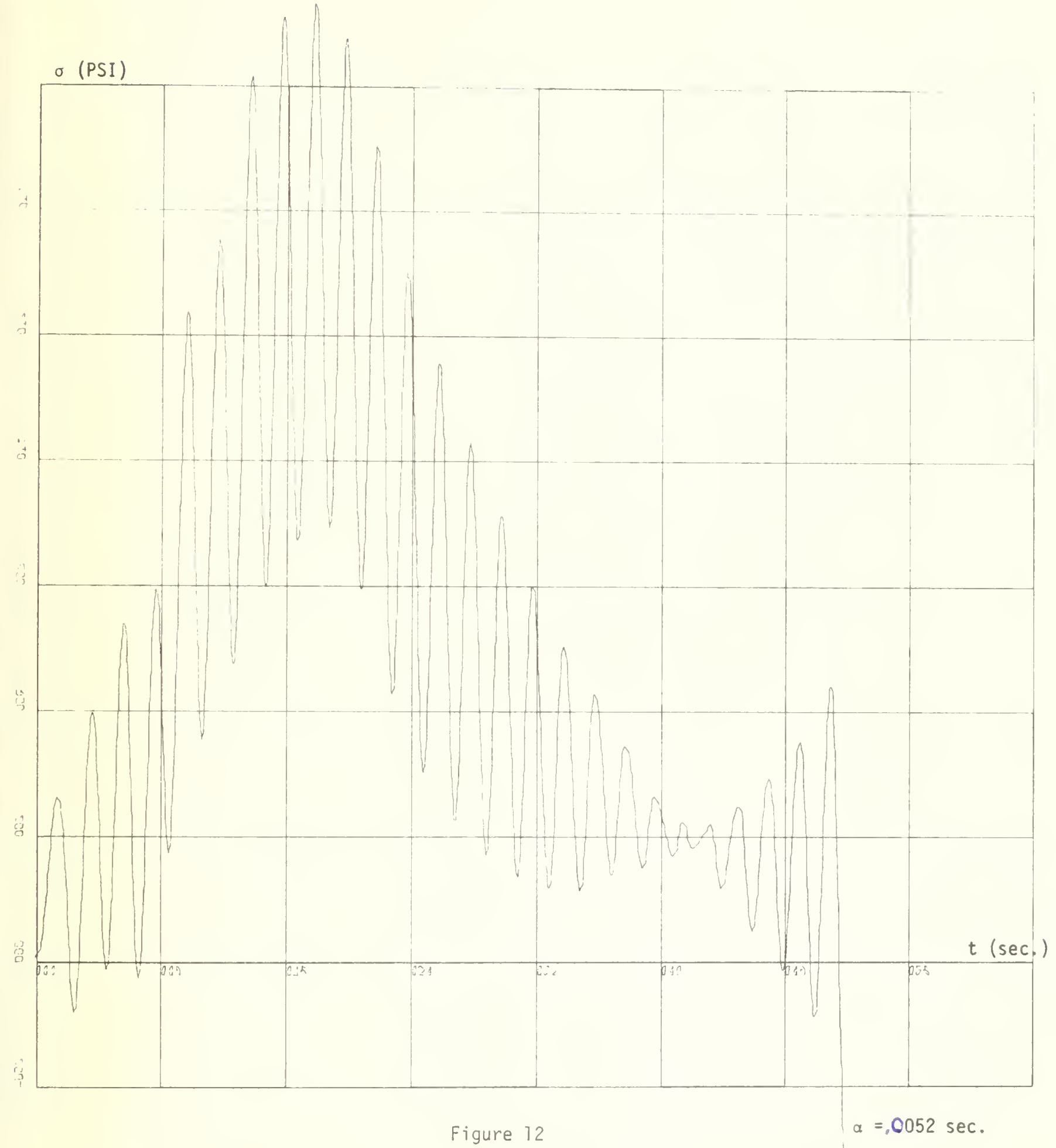

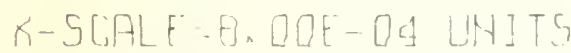

$\checkmark-5$ S.ALLF-3. DOF + DI UNITS

AXIAL WAUE PROPACATION-STRESSES AT $X / L=1 / 4$. 



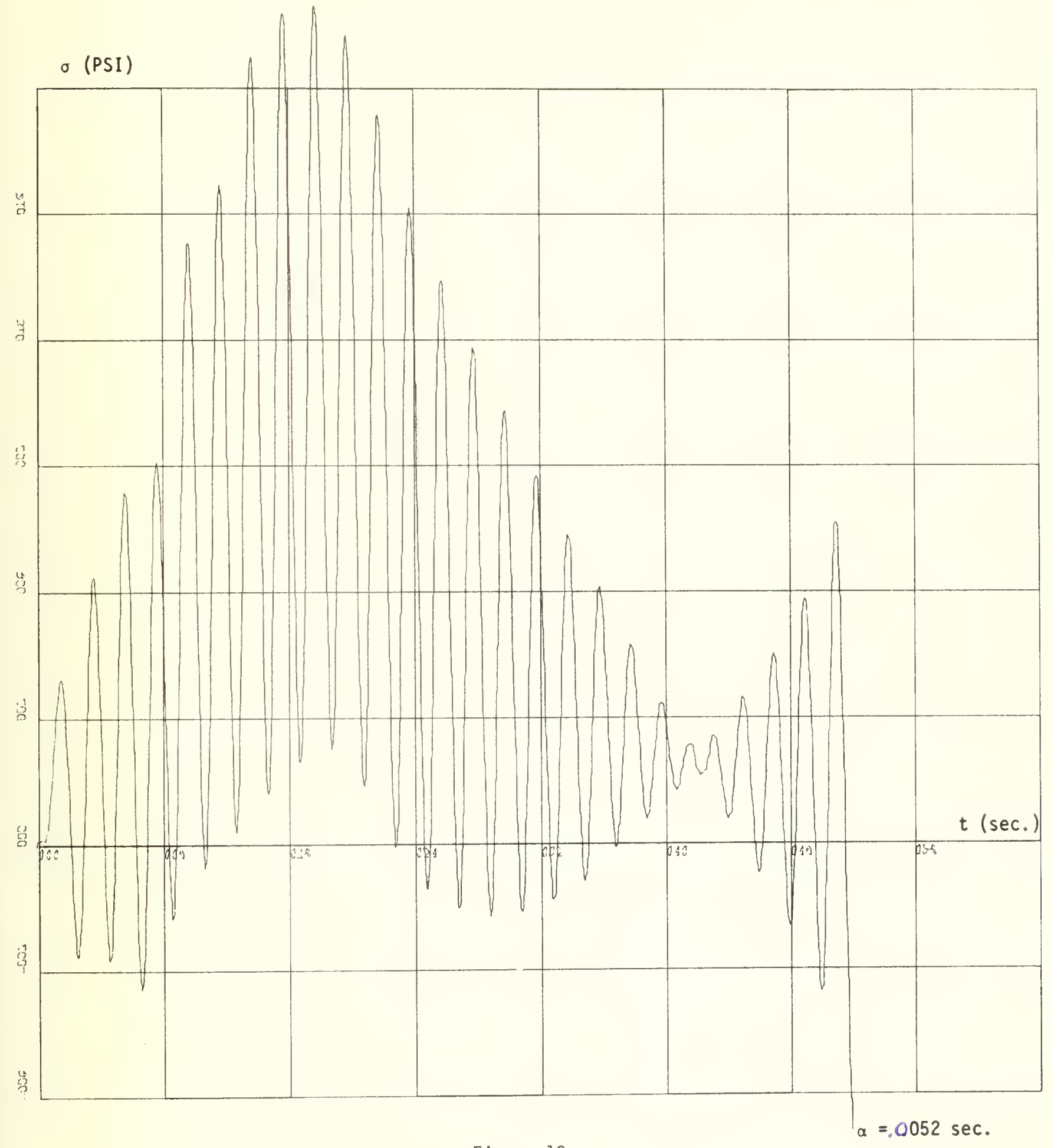

Figure 13

$X-S C$ SALE:- - . QOEE-QA UNJTS

$Y-S C$ ALF $=3, Q Q E+\square \perp$ UN]TS

AX'IAL WAUE PRMPAGATION-STRESSES AT $x / L=1 / 2$. 



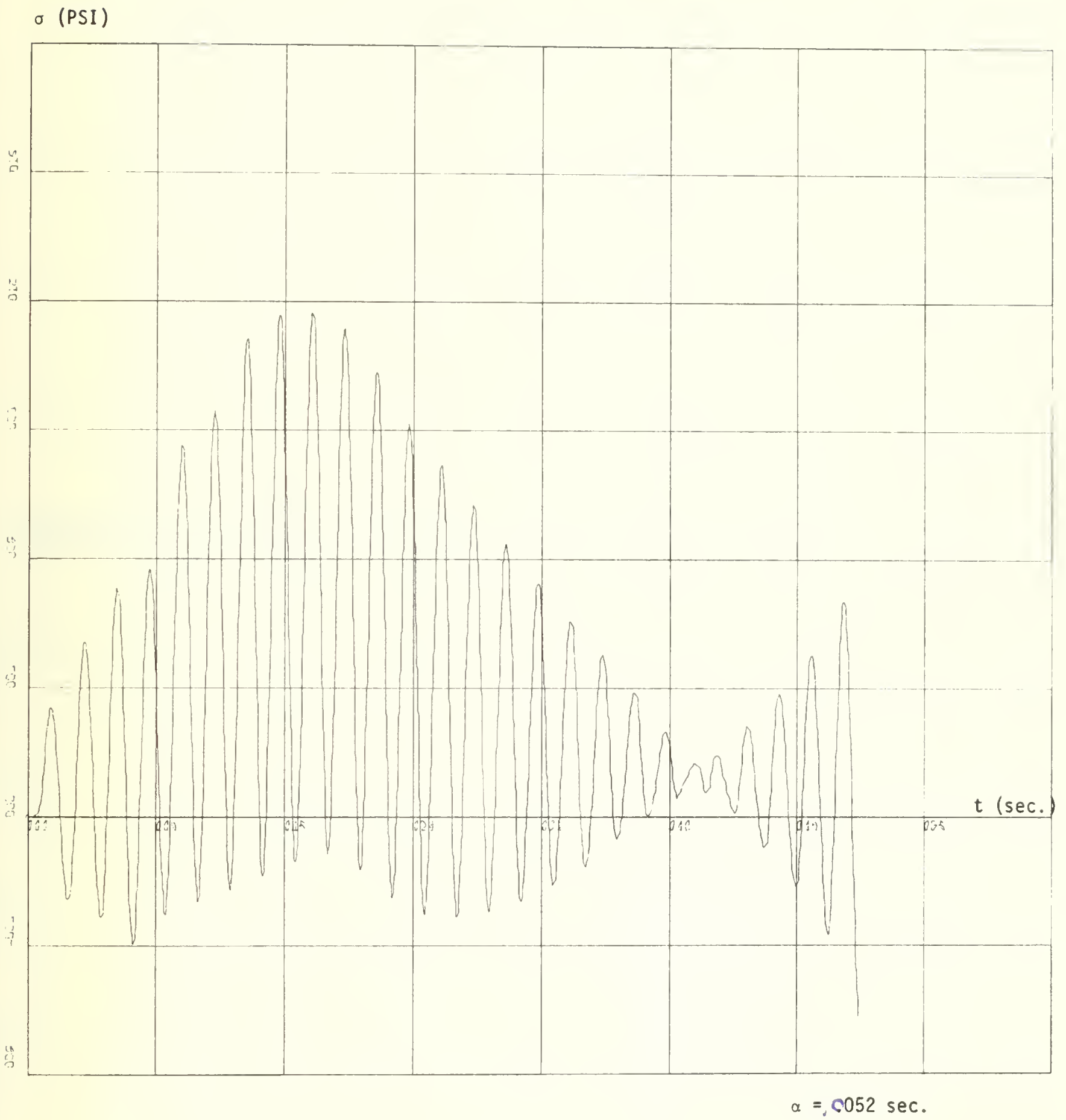

Figure 14

Y'-SCRLF-P. DOE-0A LNITS

Y-SLIFL.F-3: QQDE + D.1 LNITS

AXIAL HAUE PROPAGATIOYYSTRESSES AT $K L_{-}{ }^{3 / 4}$ 



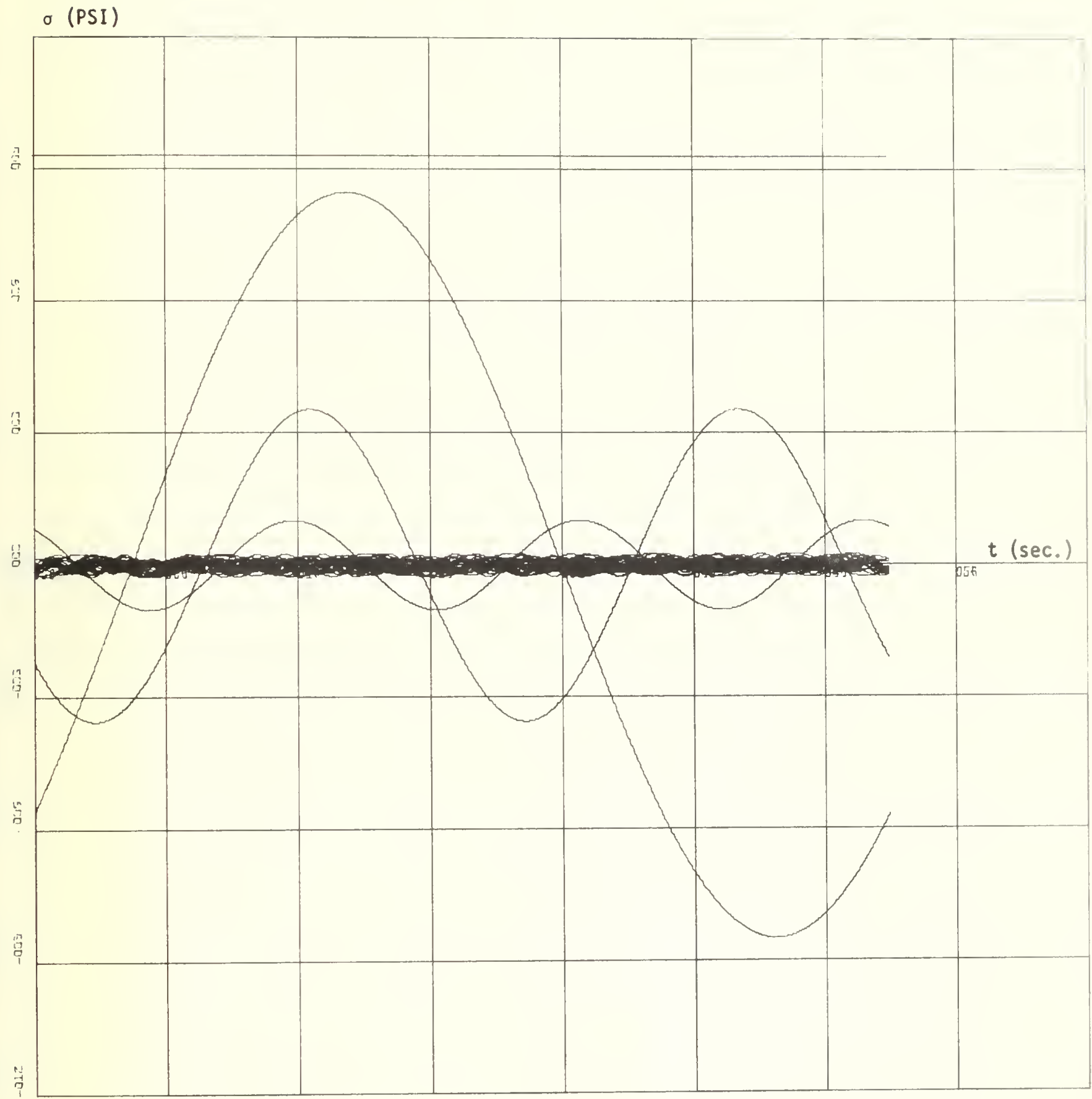

Figure 15

$a=.0052 \mathrm{sec}$.

K-SEALE:=8.00E-O4 UNITS

$Y-$ SCALE $=3$. QOE + Q UNITS

AXIAL WAUE PROPALATIDN-HARMDUNCS at $x / L=0$. 





Figure 16

$a=.0052 \mathrm{sec}$.

$X$-SCALE $=8.00 E-04$ UNITS

$Y$-SCALE $=3.00 E+01$ UNITS

AXIAL WFUE PROPAGATION-HARMONICS at $x / L=1 / 2$. 

No. Copies

1. Defense Documentation Center

Cameron Station

Alexandria, Va 22314

2. Library

Code 0212

Naval Postgraduate School

Monterey, Ca 93940

3. Naval Weapons Center

China Lake, Ca 93555

Attn: John O'Malley

Ray Miller, Code 457

Howard Gerrish, Code 4545

Bob Dillinger/Dwight Weathersbee, Code 4573

4. Naval Weapons Laboratory

Dahlgren, Va 22448

Attn: Ken Thorsted, Code GL

5. Naval Ordnance Systems Command

Navy Department

Washington, D. C. 20360

Attn: j. Murrin, Code ORO 3370

Z. Levensteins, Code ORD 032

Conte 035

6. Naval Air Systems Command

Navy Department

Washington, D. C. 20360

Attn: Code 320

7. Asst. Prof. David Salinas

Mechanical Engineering Department

Naval Postgraduate School

Monterey, Ca 93940

8. Assoc. Prof. R. E. Ball

Aeronautics Department

Naval Postgraduate School

Monterey, Ca 93940

9. Chairman

Department of Aeronautics

Naval Postgraduate School

Monterey, Ca 93940 

10. Chairman

Department of Mechanical Engineering

Naval Postgraduate School

Monterey, California 93940

11. Dean of Research

Code 023

Naval Postgraduate School

Monterey, Ca 93940 

U152118 
56853010581093 